\title{
The benefits and costs of a master's programme in primary health care: a cross-sectional postal survey
}

Zoi Tsimtsiou, Kalwant Sidhu and Roger Jones

\author{
ABSTRACT \\ Background \\ Master's programmes can provide continuing \\ professional development, equipping GPs to teach, \\ research, and lead general practice. A previous \\ evaluation of the MSc in primary health care found that \\ graduates were contributing significantly to the \\ discipline of general practice. Given the changes in \\ general practice over the last 10 years, it was \\ considered useful to investigate longer-term outcomes. \\ Aim \\ To assess the benefits GPs have derived from the MSc \\ in terms of the intended learning outcomes and their \\ own plans for involvement in research and teaching. \\ Design of study \\ A cross-sectional survey using a postal questionnaire. \\ Setting \\ Department of Primary Care and Public Health \\ Sciences, King's College London. \\ Method \\ A postal questionnaire was sent to the graduates of \\ MSc in primary health care from 1997 until 2008. \\ Results \\ A total of 50 completed questionnaires were returned \\ (response rate $76 \%$ ). After graduation, 22 GPs had \\ completed another degree or diploma and 21 had work \\ accepted for publication, resulting in 74 papers. Nine \\ held academic posts at lecturer or senior lecturer level, \\ 21 were GP trainers, and 21 undergraduate teachers. \\ Twenty-five GPs held more than one teaching-related \\ post. The majority of the graduates confirmed the \\ attainment of the MSc's intended outcomes. Positive \\ influences of the MSc were identified, including career \\ development, personal development, and job \\ satisfaction.

\section{Conclusion} \\ Graduates reported a number of benefits to \\ themselves, their practices, and their patients. As the \\ requirements for continuing professional development \\ of GPs become more stringent, and with the advent of \\ revalidation, the current ad hoc approach to career \\ development in general practice is becoming \\ unsustainable. To enhance its credibility as an \\ academic discipline, general practice must continue to \\ develop its capacity for research and scholarship. \\ Master's programmes are likely to have an important \\ role in supporting professional development in general \\ practice in the future.

\section{Keywords} \\ education; general practitioners; medical, research; \\ primary health care; training.
}

\section{INTRODUCTION}

General practice in the UK is undergoing major changes, with proposals for extending postgraduate training, new roles for practitioners, new methods of delivering primary care, and the imminent introduction of revalidation and relicensing of all doctors. ${ }^{1-4} \mathrm{~A}$ wide range of career opportunities has opened up for GPs, ${ }^{3}$ but there is still no explicit career pathway to support these developments. Master's programmes (MScs and MAs) provide continuing professional development (CPD), equipping GPs to teach, research, and lead general practice, but do they really represent a credible career escalator? This study explores graduates' perceptions of the benefits and costs of undertaking a specific MSc.

For the last 21 years, King's College London has run an MSc in primary health care, which evolved from the United Medical and Dental School (UMDS) MSc in general practice. The MSc is designed to enable primary healthcare professionals to critically examine key aspects of their work, and to develop academic and leadership skills in education, research, and service delivery, facilitating highquality patient-centered care. ${ }^{5}$

$Z$ Tsimtsiou, $M D, M S c, P h D$, honorary research fellow; $K$ Sidhu, DipCOT, PGCHE, MA, PhD, programme director in postgraduate medical education; R Jones, DM, FRCGP, Emeritus Professor, King's College London, Department of Primary Care and Public Health Sciences, London.

Address for correspondence

Dr Kalwant Sidhu, King's College London, Department of Primary Care and Public Health Sciences, Capital House, 42 Weston Street, London SE1 3QD.

E-mail: kalwant.sidhu@kcl.ac.uk

Submitted: 11 November 2009; Editor's response: 22 December 2009; final acceptance: 1 April 2010.

(c)British Journal of General Practice.

This is the full-length article (published online 1 November 2010) of an abridged version published in print. Cite this article as: Br J Gen Pract 2010; DOI: 10.3399/bjgp10X532576. 
An evaluation of the first nine cohorts of the MSc in 1997 found that graduates were contributing significantly to the discipline of general practice; two-thirds were engaged in research, and over half reported having had work accepted for publication. ${ }^{6,7}$ Given the major changes in general practice over the last 10 years, it was decided that it would be useful to investigate the longer-term outcomes in a further 10 cohorts of graduates.

\section{METHOD}

All the GPs who graduated from 1997 until 2008 were eligible to participate in the study. An invitation letter, information sheet, questionnaire for the study, and reply-paid envelope were posted to 66 graduates. A postal reminder was sent after 15 days, and a final email reminder was sent a month after the initial invitation. Contact details could not be found for seven graduates.

The questionnaire included questions about changes in working arrangements since graduation, current appointments, research involvement, teaching activity, the importance of the group experience, and the overall achievement of their own initial goals. A question was also included about sources of funding for fees and locum costs. An 18-item instrument was used to measure the attainment of the MSc's intended outcomes, ${ }^{6,7}$ using a 5 -point Likert scale ( $1=$ disagree, $5=$ agree). In addition to quantitative data, participants were invited to write freely about the way the programme had influenced their personal and professional development and their practice. Information about mean age at entry, sex, medical school of graduation, research and teaching activity prior to the application to study, size of practice in which they worked when they applied, and their reasons for applying were collected from their application forms, which were accessed with their consent.

Analysis of the qualitative data deriving from freetext answers was conducted using thematic content analysis. All transcripts were searched until no new themes emerged. ${ }^{8}$ The first author did the analysis, and the second author checked the analysis independently. The data are presented using quotes that were considered illustrative of the themes. The quantitative data frequency analysis and the cross-tabulation of initially stated reasons for applying and achievement of intended outcomes were conducted using the Statistical Package for the Social Sciences (SPSS version 15.0).

\section{RESULTS}

Completed questionnaires were returned by 50 graduates (response rate $76 \%$ ).

\section{How this fits in}

A wide range of career opportunities have opened up for GPs, but there is stil no explicit career pathway to support these developments. The Tooke report recommended major changes in training for general practice, and revalidation and relicensing will soon represent further challenges. This study adds to the evidence that master's programmes can equip GPs with skills and knowledge that are beneficial for professional and personal development as well as patient care.

\section{Characteristics of the graduates}

The mean age of the GPs at entry was 40.1 ( \pm 6.6 , range: 29-54) years. They had 11 ( \pm 6.9 , range: 1-25) years of experience in general practice, starting from the beginning of their vocational training. Thirty-one were male, and 41 had graduated from a UK medical school.

\section{Funding sources}

Forty of the GPs had received some kind of financial support for programme fees, and 30 for the locum costs. Details are presented in Table 1. The 'salaried practitioner scheme' was funded by three London primary care trusts (PCTs) to enhance recruitment and retention of GPs. Prolonged studyleave funding still exists but its availability is dependent on the individual PCT.

\section{Research and teaching commitments}

At the time of the survey, 22 of the responders were not working in the same practice as when they started the MSc, and eight of them considered that this could be related to the MSc. Although the questionnaire did not include a specific question on the reduction of clinical commitments, four GPs referred to its influence in reducing these commitments to pursue academic interests or to achieve a better balance between work and leisure. After completion of the MSc, 22 graduates had registered for another degree or diploma: three for a $\mathrm{PhD}$, two for an MD, two for another MSc, two for

Table 1. Sources of GPs' funding of MSc programme fees and locum costs.

\begin{tabular}{lcc} 
Source & Programme fees, $n$ (\%) & Locum costs, $n$ (\%) \\
\hline Totally self-funded & $9(18.3)$ & $7(18.3)$ \\
\hline Prolonged study leave & $16(32.7)$ & $17(18.3)$ \\
\hline Salaried practitioner scheme & $8(16.3)$ & $0(0)$ \\
\hline Bursary/sponsorship & $12(24.5)$ & $6(18.3)$ \\
\hline Other & $4(8.2)$ & $7(18.3)$ \\
\hline Total & 49 & 37 \\
\hline
\end{tabular}

aLIZEI (London Initiative Zone Educational Incentives), small grants from various sources. 
Table 2. Graduates' views on intended outcomes.

\begin{tabular}{|c|c|c|}
\hline Learning outcome & Rank & $\begin{array}{c}n(\%) \text { who could } \\
\text { not agree }\end{array}$ \\
\hline The MSc has enabled me to be more critical of issues with my own work and that of others & $=1$ & $2(4)$ \\
\hline The MSc has increased my awareness of ethical issues & $=1$ & $2(4)$ \\
\hline The MSc has helped me to use evidence in my clinical practice & $=2$ & $4(8)$ \\
\hline The MSc has increased my understanding of patients' beliefs and behaviour & $=2$ & $4(8)$ \\
\hline The MSc has helped me to evaluate published research & $=3$ & $5(10)$ \\
\hline The MSc has enhanced my capacity for reflection & $=3$ & $5(10)$ \\
\hline The MSc has added to my job satisfaction & $=4$ & $6(12)$ \\
\hline The MSc has given me new insight into my own process of learning & $=4$ & $6(12)$ \\
\hline The MSc has enhanced my ability to deal with ethical issues & $=4$ & $6(12)$ \\
\hline The MSc has given me new insight into my own process of clinical reasoning & 5 & $7(14)$ \\
\hline The MSc has increased my confidence as a teacher & $=6$ & $8(16)$ \\
\hline The MSc has added to my enjoyment of my work & $=6$ & $8(16)$ \\
\hline The MSc has helped me to identify and implement good practice & 7 & $12(24)$ \\
\hline The MSc has increased my confidence as a doctor & 8 & $13(26)$ \\
\hline The MSc has enabled me to provide a better quality of care to my patients & $=9$ & $18(36)$ \\
\hline The MSc has improved my communication with patients & $=9$ & $18(36)$ \\
\hline The MSc has helped me to understand how clinical governance relates to clinical practice & 10 & $21(42)$ \\
\hline Other members of my practice have benefited from my doing the MSc & 11 & $25(50)$ \\
\hline
\end{tabular}

an MA, eight for diplomas, and eight for certificates; two became members of the Royal College of General Practitioners (MRCGP), and one was awarded the College's fellowship.

Eleven of the GPs are currently engaged in research projects; a further six have been named on research grants, and 21 have published their work after completing the MSc. Twenty-one have published journal articles (74 papers in total). Seven have contributed to books or book chapters (13 in total), nine have presented papers at conferences (57 in total), and six have presented conference posters (29 in total).

Teaching or academic posts held by the graduates currently or after the completion of the MSc include: nine at lecturer/senior lecturer level, 21 undergraduate teachers, 21 GP trainers, 13 course organisers or trainers, 6 MRCGP examiners, 4 GP tutors, 2 honorary research fellows, and 17

Table 3. Achievement of initial individual goals.

\begin{tabular}{lcc} 
Initial goal & $\begin{array}{c}\text { Attained by (number } \\
\text { of graduates) }\end{array}$ & \begin{tabular}{c} 
Total \% \\
\hline Career development
\end{tabular} \\
\hline Personal development & $26(42)$ & 83 \\
\hline Improvement in clinical practice & $14(16)$ & 88 \\
\hline Increase in job satisfaction & $10(12)$ & 88 \\
\hline Understanding the changing concept of general practice & $15(15)$ & 83 \\
\hline The group experience & $6(7)$ & 100 \\
\hline Setting goals for the benefit of their practice & $2(2)$ & 100 \\
\hline
\end{tabular}

other teaching posts. Twenty-five held more than one of the above posts.

Twenty-eight graduates recognised the MSc as the key factor in attaining their current teaching or research roles. Among the GPs holding academic posts, all recognised the MSc as a key factor in climbing the academic ladder.

\section{Achievement of goals and educational outcomes}

The majority of the 18 items of the MSc's intended outcomes were rated as having been achieved (Table 2). A more critical outlook on practice, and awareness of ethical issues were highly ranked. The use of evidence in clinical practice and understanding patients' behaviours and beliefs also scored highly, affirming the programme's objectives to develop both academic excellence and highquality patient care.

The majority of the graduates $(n=40)$ stated that they had achieved their own initial goals, with career development being the most frequently cited aim. Improvement in clinical practice, increased job satisfaction, and a better understanding of the changing nature of general practice were also cited as important goals (Table 3).

Forty-seven graduates thought the group experience had been a significant aspect of the MSc. The free-text answers provided a better insight about the ways the MSc influenced their development. A selection of quotes that are illustrative of these themes are presented in Box 1 , 


\section{Box 1. Quotes that are illustrative of the themes identified relating to the way the} MSc has influenced GPs' development.

\section{Benefits to individual GP}

- Career development:

'Realised I loved sharing knowledge and this led me to teaching.' (GP54)

'The MSc stimulated an interest in research, and I had always been interested.' (GP69)

- Personal development:

'Investment in oneself brings unexpected rewards.' (GP62)

'Made me understand what sort of person I am, my strengths, weaknesses, areas for development. Gave me confidence.' (GP52)

"The MSc gave an opportunity to take "time out" from everyday practice and reflect (take stock/analyse what we do - how and why. It has made me more reflective (analytic/critical ... I also continue to learn as an adult ...' ( GP46)

- Understanding the context of general practice:

'More awareness of external pressures on healthcare systems, allowing understanding of why we are being subjected to unreasonable changes, and to cope with it better without agreeing or colluding.' (GP64)

- Increased job satisfaction:

'I was overstretched and in danger of burnout clinically and I was becoming impatient with patients. It enabled me to step back and become more reflective and regain pleasure in my work (by doing less in the practice and varying my work to include more social development). A really good experience. I continue to practice. More happily and patiently.' (GP50)

\section{Benefits to patients}

- Improving clinical practice:

'More evidence based but a wider appreciation of the individual patient too.' (GP45)

'I am better able to evaluate evidence, especially treatments and probably prescribe even less since the MSc.' (GP67)

'Gave me a more critical approach to daily practice, with better understanding of conflicting evidence. The MSc influenced my approach to problem solving and uncertainty.' (GP58)

\section{Benefits to practice}

- Benefits for the practice

'Our practice has become a hot bed for teaching and education. We are looking to rebuild and have a "training suite".' (GP54)

'Becoming a training practice has improved standards.' (GP22)

and suggest that development was wide ranging, embracing both academic and clinical practice, and personal and professional dimensions. The student group itself provided an ongoing source of support.

\section{DISCUSSION}

\section{Summary of main findings}

The study findings suggest that the MSc had a positive overall effect in a number of different areas. Most benefits were identified at an individual level. Personal development was reflected in increased confidence, stimulating interest in new career pathways as well as increased job satisfaction for existing posts. Benefits to patient care were manifested through graduates' better understanding of research evidence and psychosocial concepts of ill health, as well as a more critical and self-reflective approach to practice. Benefits for the practice were reported by only half of the graduates, although the qualitative data suggest that the outcomes impact positively on the wider practice environment. A contribution to the discipline of general practice was also significant. The graduates represent a dynamic group of GPs with a better insight into the changes taking place in primary care, and a substantial input into research projects and academic publications, as well as in undergraduate and postgraduate education. The majority of the GPs were enabled to undertake the MSc with some financial support in terms of course fees and locum costs. 


\section{Strengths and limitations of the study}

Several limitations may affect the interpretation of the study findings. The study is based on an evaluation of a single master's programme, and although some of the findings are supported by existing literature, it would have been useful to compare outcomes from other MScs. A small number of the study graduates were not accessible. The response rate of $76 \%$ suggests that the sample was representative, although it is not possible to exclude the possibility that responders felt more positive than non-responders. The time since graduation was not the same for all responders, and the impact of the MSc, especially in terms of career development, may not be fully apparent for those in the latest cohorts. Finally, although the GPs in the study perceived the benefits to be wide ranging, further research would need to be undertaken to quantify the actual benefits to patients and practice.

\section{Comparison with existing literature}

The benefits to individual GPs, embracing career and personal development, were most notable. Enhanced research skills, personal development, increased job satisfaction, and the enjoyment and support of the group were frequently mentioned, in line with previous reports. ${ }^{6,7,9,10}$ Isolation in general practice can be not only geographical, but also intellectual, and group-based approaches that provide a supportive environment ${ }^{11}$ have been suggested as a means of dealing with the problems associated with isolation and diminishing job satisfaction. ${ }^{12}$

Factors associated with providing better quality of patient care included the adoption of a more patient-centred approach and the use of evidence in clinical practice, corresponding to previous studies. ${ }^{9,10,13}$ However, improvement in clinical practice had been among the initial goals for less than one-third of GPs, and as a discrete learning outcome, 'quality of patient care' was not ranked highly. This may reflect the fact that the study expression of the learning outcome fails to capture the multifaceted nature of patient care. The study would argue that MScs that are not primarily 'clinical' can also have positive outcomes for patient care.

The study GPs' aspirations for career development may have been at odds with affording any benefit to the existing practice team. Only three GPs had initially set goals related to their primary care team. However, half of the graduates stated that other members of the practice had gained from the MSc, often facilitating the practice's development to training status. .,9,10
The MSc enlarged the pool of potential GP teachers, researchers, and academics. The relatively small number of GPs active in research (compared with the previous cohorts) may reflect the changes that the new general practice contract of 2004 imposed, possibly enabling fewer research activities within the GP's clinical routine. This could also be an artefact of short follow-up time since graduation. ${ }^{6}$ Although a few graduates mentioned that they have reduced their clinical commitments to pursue academic interests, the study results do not suggest that postgraduate qualifications lead to an absolute loss from general practice, rather that additional roles in education and research are undertaken. In today's NHS, it is essential that such a group of GPs is developed to sustain the academic credibility of general practice and provide evidence underpinning primary health care. ${ }^{14}$

Most of the GPs $(n=40)$ had been able to obtain financial support for the course fees and locum costs. Prolonged study leave provides substantial funding for undertaking postgraduate study, but may not always be available. ${ }^{15}$ With diminishing sources of external funding for GPs, it is unclear whether master's programmes will continue to be viable options for continuous professional development. Looking beyond financial cost, Pitts and Vincent ${ }^{16}$ surveyed GPs who had expressed an interest in attending a postgraduate programme but then failed to enrol. They suggested that demotivating factors were predominantly related to external issues such as family and practice demands. The emergence of a defined and integrated career structure for GPs could mitigate these factors as well as addressing the ad hoc approach to funding.

\section{Implications for clinical practice}

Master's programmes could have an important role in supporting professional development in general practice in the future, yielding benefits that go beyond the individual GP. These benefits come at a cost, measurable financially in terms of programme fees and locum replacement costs, but more broadly measurable in terms of the pressures and demands of undertaking additional work. However, the greater cost may be to the profession if it cannot facilitate the development of leadership and academic capacity, which is fundamental to the development of practice. ${ }^{14}$ The current lack of career structure means that CPD is potentially perceived as something additional rather than integral to professional practice. With the requirements of revalidation, the current ad hoc approach will be unsustainable. ${ }^{17}$ Following the Tooke report, ${ }^{2}$ vocational training is under review, 
giving the profession the opportunity to consider whether higher professional education continues to be an optional extra for some GPs, or whether it should be available as part of a better defined career for all GPs. ${ }^{18}$ It would be possible, for example, to integrate an MSc into the third and fourth years of vocational training for selected trainees. Transferable arrangements within master's programmes might also offer an attractive structured approach to CPD for some doctors. The profession needs to embrace this opportunity to fully integrate the requirements for clinical and academic excellence.

\section{Funding body}

None.

\section{Ethics committee}

This study was approved by the King's College London Research Ethics Committee.

\section{Competing interests}

The authors have stated that there are none.

\section{Acknowledgements}

We are grateful to all the MSc graduates who responded enthusiastically to our invitation. We also gratefully acknowledge Beryl Stevens, MSc administrator, for her assistance for this study.

\section{Discuss this article}

Contribute and read comments about this article on the Discussion Forum: http://www.rcgp.org.uk/bjgp-discuss

\section{REFERENCES}

1. Department of Health. High quality health for all: NHS next stage review: our vision for primary and community care. Final report. London: Department of Health, 2008.

2. Tooke J. Aspiring to excellence: final report of the independent inquiry into modernizing medical careers. London: MMC Inquiry, 2008. http://www.mmcinquiry.org.uk/Final_8_Jan_08_MMC_all.pdf (accessed 19 Apr 2010).

3. Hilton $\mathrm{S}$, Carter Y. Academic careers in general practice and primary care. Med Educ 2000; 34(11): 910-915.

4. Loudon I, Horder J, Webster C. General practice under the National Health Service: 1948-1997. London: Clarendon Press Oxford, 1988.

5. King's College London. Masters in primary health care. http://www.kcl.ac.uk/schools/medicine/research/hscr/sections/primar ycare/msc/index.html (accessed 1 Oct 2010).

6. Calvert $\mathrm{G}$, Britten $\mathrm{N}$. The UMDS MSc in general practice: attainmen of intended outcomes. Br J Gen Pract 1998; 48(436): 1765-1768.

7. Calvert G, Britten N. The United Medical and Dental School of Guy's and St Thomas' Hospitals' MSc in general practice: graduates' perspectives. Med Educ 1999; 33(2): 130-135.

8. Bowling A. Research methods in health. Buckingham: Open University Press, 1997.

9. Illing J. Taylor G, O'Halloran C. Can a postgraduate course for general practitioners deliver perceived benefit for learners, patients and the NHS? A qualitative study. Med Teach 2002; 24(1): 67-70.

10. Taanila A, Larivaara P, Korpio A, Kalliokoski R. Evaluation of a family-oriented continuing medical education course for general practitioners. Med Educ 2002; 36(3): 248-257.

11. Smith LF, Eve R, Crabtree R. Higher professional education for general practitioners: postal questionnaire survey. Br J Gen Pract 2000; 50(453): 288-292.

12. Millac J. Continuing medical education. J R Coll Gen Pract 1985 35(275): 303-304.

13. Schattner P, Klein L, Piterman L, et al. Impact of Master of Family Practice degree by distance learning on general practitioners' career options. Med Teach 2007; 29(4): e85-e92.

14. Mathers N, Carter Y, Marshall M. New century, new challenges. Fam Pract 2003; 20(4): 360-261.
15. Hastie A, Stephenson A. Choosing general practice: your career guide. Oxford: BMJ Books, Blackwell Publishing, 2008

16. Pitts J, Vincent S. General practitioners' reasons for not attending a higher professional education course. Br J Gen Pract 1994; 44(383): 271-273.

17. Department of Health. Trust, assurance and safety - the regulation of health professionals in the 21st century. London: HMSO, 2007.

18. Kochen MM, Himmel W. Academic careers in general practice: scientific requirements in Europe. Eur J Gen Pract 2000; 6(2): 62-65. 